\title{
PENTINGNYA PENGETAHUAN PERAWAT AKAN PELAKSANAAN KESEHATAN DAN KESELAMATAN KERJA (K3) DI RUMAH SAKIT Josephine Tamara Gloria \\ josephinetamara18@gmail.com
}

\section{LATAR BELAKANG}

Perawat merupakan petugas kesehatan dengan presentasi terbesar dan memegang peranan penting dalam pemberian pelayanan kesehatan. WHO (2013) mencatat, dari 39,47 juta petugas kesehatan di seluruh dunia, 66,7\%-nya adalah perawat. Di Indonesia, perawat juga merupakan bagian terbesar dari tenaga kesehatan yang bertugas di rumah sakit yaitu sekitar 47,08\% dan paling banyak berinteraksi dengan pasien (Depkes RI, 2014). Ada sekitar dua puluh tindakan keperawatan, delegasi, dan mandat yang dilakukan dan yang mempunyai potensi bahaya biologis, mekanik, ergonomik, dan fisik terutama pada pekerjaan mengangkat pasien, melakukan injeksi, menjahit luka, pemasangan infus, mengambil sampel darah, dan memasang kateter.

Rumah sakit merupakan salah satu tempat pasien berobat/dirawat, di tempat ini pasien mendapatkan terapi dan perawatan sampai sembuh. Rumah sakit juga merupakan depot dari berbagai macam penyakit yang berasal dari pasien, perawat, dokter, pengunjung yang berstatus karier. Rumah sakit sebagai industri jasa yang mempunyai beragam persoalan tenaga kerja yang rumit dengan berbagai risiko terkena penyakit akibat kerja bahkan kecelakaan akibat kerja sesuai jenis pekerjaannya, sehingga berkewajiban menerapkan upaya Keselamatan dan Kesehatan Kerja Rumah Sakit (K3RS). Namun, fenomena banyak ditemukan bahwa kebijakan, perencanaan serta pelaksanaan K3RS tampaknya belum terlaksana secara maksimal sesuai standar, sehingga pekerja rumah sakit banyak mengalami masalah kesehatan dan keselamatan kerja.

Kesehatan dan keselamatan kerja merupakan salah satu isu penting di dunia kerja saat ini. Hasil riset yang di lakukan oleh badan dunia ILO menyebutkan bahwa setiap hari rata-rata 6.000 orang meninggal, setara dengan satu orang setiap 15 detik atau 2,2 juta orang per tahun akibat sakit atau kecelakaan yang berkaitan dengan pekerjaannya (Rahayuningsih \& Hariyono, 2011). 
Potensi bahaya di RS, selain penyakit-penyakit infeksi juga ada potensi bahaya-bahaya lain yang mempengaruhi situasi dan kondisi di RS, yaitu kecelakaan (peledakan, kebakaran, kecelakaan yang berhubungan dengan instalasi listrik, dan sumber-sumber cedera lainnya), radiasi, bahan-bahan kimia yang berbahaya, gas-gas anastesi, gangguan psikososial dan ergonomi.Semua potensi bahaya tersebut diatas, jelas mengancam jiwa dan kehidupan bagi para karyawan di RS, para pasien maupun para pengunjung yang ada di lingkungan RS (Teguh, 2008).

Tenaga medis rumah sakit mempunyai resiko 2-3 kali lebih besar terkena infeksi nosokomial. Kejadian infeksi nosokomial yang diakibatkan karena perilaku K3 petugas medis yang belum maksimal di beberapa wilayah Indonesia antara lain Jakarta 41,1\% kasus, Surabaya 73,3\% dan Yogyakarta $5,9 \%$ kasus dari total sampel yang diambil peneliti (Hasyim,2005). Apabila dihitung kerugian yang dialami seluruh rumah sakit di Indonesia, dengan kondisi sanitasi dan K3RS yang masih belum memadai, akan sangat besar. Untuk mengatasi hal tersebut perlu ditingkatkan upaya K3RS salah satunya dengan meningkatkan perilaku K3 pada semua komponen yang ada di rumah sakit (Widajati, 2010).

\section{METODE}

Metode yang digunakan oleh penulis adalah literature review dengan cara melakukan analisis, eksplorasi, dan kajian bebas dari berbagai jurnal, text book, maupun e-book yang relevan dan berkaitan dengan materi pembelajaran yaitu pentingnya pengetahuan perawat akan pelaksanaan kesehatan dan keselamatan kerja (K3) di rumah sakit.

Artikel ataupun jurnal yang digunakan pada literature review ini adalah artikel atau jurnal yang didapatkan dari google scholar dan google book yang diterbitkan selama 8 tahun terakhir penerbitan. Dalam mencari literature review, menggunakan kata kunci pengambilan keputusan keperawatan dan perawat.

\section{HASIL}

Kesehatan dan Keselamatan Kerja (K3) adalah instrumen yang melindungi pekerja, perusahaan, masyarakat dan lingkungan dari hal-hal merugikan yang dapat ditimbulkan oleh aktivitas pekerjaan. Bagi pekerja, K3 melindungi mereka dari bahaya yang terjadi selama proses bekerja dan juga efek kesehatan jangka panjang. Bagi perusahaan K3 bertujuan untuk mencegah kerugian yang ditimbulkan oleh kecelakaan kerja yang dapat menghambat produksi dan produktivitas kerja. 
Keselamatan Kerja (K3) merupakan salah satu isu penting di dunia kerja saat ini termasuk di lingkungan rumah sakit. Kecelakaan kerja dapat diakibatkan karena rendahnya pengetahuan pekerja tentang suatu teknik keselamatan dan kesehatan kerja di lingkungan kerja. Dalam Undang-Undang Nomor 23 Tahun 2003 tentang Kesehatan, Pasal 23 dinyatakan bahwa upaya Kesehatan dan Keselamatan Kerja (K3) harus diselenggarakan di semua tempat kerja, khususnya tempat kerja yang mempunyai risiko bahaya kesehatan, mudah terjangkit penyakit atau mempunyai karyawan paling sedikit 10 orang. Jika memperhatikan isi dari pasal di atas maka jelaslah bahwa Rumah Sakit (RS) termasuk ke dalam kriteria tempat kerja dengan berbagai ancaman bahaya yang dapat menimbulkan dampak kesehatan, tidak hanya terhadap para pelaku langsung yang bekerja di RS, tapi juga terhadap pasien maupun pengunjung RS.

Penyakit Akibat Kerja (PAK) dan Kecelakaan Kerja (KK) di kalangan petugas kesehatan dan non kesehatan kesehatan di Indonesia belum terekam dan teratasi dengan baik. Sebagai faktor penyebab, kecelakaan sering terjadi karena kurangnya kesadaran pekerja dan kualitas serta keterampilan pekerja yang kurang memadai. Banyak pekerja yang meremehkan risiko kerja, sehingga jarang menggunakan alat-alat perlindungan diri (APD) walaupun sudah tersedia.

Kesehatan dan keselamatan kerja (K3) di rumah sakit memiliki tujuan meningkatkan dan memelihara derajat kesehatan fisik, mental dan sosial setinggi-tingginya bagi pekerja di setiap jenis pekerjaan, pencegahan terhadap gangguan kesehatan pekerja yang disebabkan oleh kondisi pekerjaan, perlindungan bagi pekerja dan pekerjaannya dari resiko akibat faktor yang merugikan kesehatan, dan penempatan serta pemeliharaan pekerja. Penting bagi perawat untuk memiliki pengetahuan mengenai kesehatan dan keselamat kerja, ini dikarenakan perawat menghabiskan waktu terbanyak di sekitar pasien. Contoh potensi bahaya yang dapat mengakibatkan kecelakaan kerja yang sering dialami oleh perawat antara lain seperti teriris benda tajam, tertusuk jarum suntik, tepercik dengan darah, terpercik cairan tubuh lain (urin), terjatuh, terpeleset dan lain-lain.

Untuk mengurangi tingkat kecelakaan kerja terutama di kalangan perawat, usaha yang dapat dilakukan antara lain mengikuti pelatihan mengenai kesehatan dan keselamatan kerja, memakai alat perlindungan diri, dan melaporkan apabila terjadi kecelakaan kerja.

\section{PEMBAHASAN}


Sebelum seseorang mengadopsi perilaku maka ia harus mengerti apa arti dan manfaat perilaku tersebut bagi dirinya dan orang lain. Apabila perawat telah mengetahui pentingnya pengendalian infeksi nosokomial maka kepatuhan terhadap SOP dan peraturan yang ada akan tercipta. Perawat dengan pengetahuan yang baik akan memiliki tindakan K3 yang baik pula karena dengan tingkat pengetahuan yang baik mengetahui dan memahami dampak negatif dari infeksi nosokomial sehingga perawat akan meningkatkan kinerjanya dalam pengendalian infeksi nosokomial.

Kesehatan kerja menurut WHO/ILO (1995), kesehatan kerja bertujuan untuk peningkatan dan pemeliharaan derajat kesehatan fisik, mental dan sosial setinggi-tingginya bagi pekerja di setiap jenis pekerjaan, pencegahan terhadap gangguan kesehatan pekerja yang disebabkan oleh kondisi pekerjaan, perlindungan bagi pekerja dan pekerjaannya dari resiko akibat faktor yang merugikan kesehatan, dan penempatan serta pemeliharaan pekerja dalam suatu lingkungan kerja yang disesuaikan dengan kondisi fisiologi dan psikologisnya. Secara ringkas merupakan penyesuaian pekerjaan kepada manusia dan setiap manusia kepada pekerjaan atau jabatannya.
Tindakan tidak aman (unsafe action) adalah tindakan yang dapat membahayakan pekerja itu sendiri maupun orang lain yang dapat menyebabkan terjadinya kecelakaan yang dapat disebabkan oleh berbagai hal seperti tidak memakai APD, tidak mengikuti prosedur kerja, tidak mengikuti peraturan keselamatan kerja dan bekerja tidak hati-hati, dimana dari setiap 300 tindakan tidak aman, akan terjadi 1 (satu) kali kecelakaan yang mengakibatkan kehilangan hari kerja.

Kecelakaan kerja menjadi salah satu masalah urgen di lingkungan rumah sakit. Hal ini diakibatkan karena rumah sakit merupakan suatu unit pelayanan kesehatan yang memberikan pelayanan pada semua bidang dan jenis penyakit. Oleh sebab itu rumah sakit dituntut untuk dapat menyediakan dan menerapkan suatu upaya agar semua sumber daya manusia yang ada di rumah sakit dapat terlindungi, baik dari penyakit maupun kecelakaan akibat kerja (Ivana, Widjasena \& Jayanti, 2014).

Pemerintah melakukan berbagai upaya untuk mengatasi kecelakaan kerja di rumah sakit, salah satunya dengan dikeluarkannya Undang-Undang Nomor 23 Tahun 1992 dan Undang-Undang Nomor 36 Tahun 2009 tentang penerapan Kesehatan dan Keselamatan Kerja di rumah sakit (Kepmenkes RI, 2010, p.8). Dalam RI No 1087 Tahun 2010 
menyatakan rumah sakit perlu memberikan informasi umum rumah sakit dan fasilitas atau sarana yang terkait dengan $\mathrm{K} 3$, informasi tentang risiko dan bahaya khusus di tempat kerjanya, SOP kerja, SOP peralatan, SOP penggunaan alat pelindung diri, dan kewajibannya dan orientasi K3 di tempat kerja. Pedoman Manajemen Kesehatan dan Keselamatan Kerja menurut Peraturan Menteri Kesehatan 2007 terdiri atas meliputi langkah-langkah sebagai berikut :

1. Tahap persiapan (komitmen dan kebijakan)

Menurut keputusan Menteri Kesehatan Republik Indonesia No.432/MENKES/SK/IV/2007

Tentang Pedoman Kesehatan dan Keselamatan Kerja di Rumah Sakit, komitmen diwujudkan dalam bentuk kebijakan (policy) tertulis, jelas dan mudah dimengerti serta diketahui oleh seluruh karyawan rumah sakit.

2. Tahap perencanaan

Menurut keputusan Menteri Kesehatan Republik Indonesia No.432/MENKES/SK/IV/2007

Tentang Pedoman Kesehatan dan Keselamatan Kerja di Rumah Sakit, rumah sakit harus membuat perencanaan yang efektif agar tercapai keberhasilan penerapan sistem manajemen K3 dengan sasaran yang jelas dan dapat diukur.

3. Tahap penerapan/pelaksanaan Menurut keputusan Menteri Kesehatan Republik Indonesia No.432/MENKES/SK/IV/2007 Tentang Pedoman Kesehatan dan Keselamatan Kerja di Rumah Sakit, pelaksanaan K3 dapat meliputi penyuluhan K3 ke semua petugas RS, pelatihan K3 yang disesuaikan dengan kebutuhan individu dengan perilaku tertentu agar berperilaku sesuai dengan yang telah ditentukan sebelumnya sebagai produk akhir dari pelatihan, dan melaksanakan program K3 sesuai peraturan yang berlaku.

4. Tahap Pengukuran dan evaluasi Menurut keputusan Menteri Kesehatan Republik Indonesia No.432/MENKES/SK/IV/2007 Tentang Pedoman Kesehatan dan Keselamatan Kerja di Rumah Sakit, pada dasarnya monitoring dan evaluasi K3 di rumah sakit adalah salah satu fungsi manajemen K3 rumah sakit yang berupa suatu langkah yang diambil untuk mengetahui dan menilai sampai sejauh mana proses kegiatan K3 rumah sakit itu berjalan dan mempertanyakan 
efektivitas dan efisiensi pelaksanaan dari suatu kegiatan K3 rumah sakit dalam mencapai tujuan yang ditetapkan.

5. Tahap peninjauan ulang dan peningkatan

Menurut keputusan Menteri

Kesehatan Republik Indonesia No.432/MENKES/SK/IV/2007

Tentang Pedoman Kesehatan dan Keselamatan Kerja di Rumah Sakit, peninjauan ulang dan peningkatan oleh pihak manajemen secara berkesinambungan untuk menjamin kesesuaian dan keefektifan dalam pencapaian kebijakan dan tujuan K3.

Perilaku K3 akan tumbuh dari adanya umpan balik dari kejadian yang dianggap akan menimbulkan kecelakaan, sehingga dapat diketahui usaha antisipasi terhadap akibat yang akan datang, dan bermanfaat bagi pembelajaran organisasi dalam peningkatan K3. Tujuan dari diterapkannya K3 ini pada Rumah Sakit, menurut peraturan Menkes diatas adalah terciptanya cara kerja, lingkungan kerja yang sehat, aman, nyaman, dan dalam rangka meningkatkan derajat kesehatan karyawan RS.

Di Indonesia penelitian $\mathrm{dr}$ Joseph tahun 2005-2007 mencatat bahwa angka Kecelakaan Akibat Kerja (KAK) needle stick injury (NSI) mencapai $38-73 \%$ dari total petugas kesehatan dan prevalensi gangguan mental emosional 17,7\% pada perawat di suatu rumah sakit di Jakarta berhubungan bermakna dengan stressor kerja (Kepmenkes RI, 2010, p.11). Hasil penelitian Demak (2013) mengenai analisis penyebab perilaku aman bekerja pada perawat menyatakan bahwa bentuk perilaku tidak aman pada perawat yaitu tidak memakai sarung tangan ketika tindakan menyuntik dan memasang infuse serta tidak menggunakan sepatu yang sesuai.

Berdasarkan hasil penelitian yang dilakukan Laranova Atri, dkk (2018) menyimpulkan bahwa kecelakaan yang sering terjadi di rumah sakit tersebut yaitu tertusuk jarum suntik (39\%) ketika melakukan prosedur pengambilan darah dan pemasangan infus, terpercik cairan selain darah $(30 \%)$ saat membuang urin pasien dan terpercik darah (10\%). Potensi-potensi bahaya yang dapat mengakibatkan kecelakaan kerja antara lain seperti teriris benda tajam, tertusuk jarum suntik, tepercik dengan darah, terpercik cairan tubuh lain (urin), terjatuh, terpeleset dan lain-lain. Tindakan memasang infus memiliki 3 risiko, yaitu luka tusuk, kontak dengan darah pasien, dan postur janggal (membungkuk). Tindakan memasang infus memiliki 3 risiko, yaitu luka tusuk, kontak dengan 
darah pasien, dan postur janggal (membungkuk).

Untuk mengurangi atau menghilangkan bahaya yang dapat menyebabkan kecelakaan di tempat kerja maka diperlukan suatu 9 manajemen risiko kegiatannya meliputi identifikasi bahaya, analisis potensi bahaya, penilaian risiko, pengendalian risiko, serta pemantauan dan evaluasi. Dalam proses identifikasi dan melakukan analisis potensi bahaya maka dapat dilakukan dengan menggunakan metode Hazard and Operability Study (HAZOP). Sementara itu pelatihan pelatihan K3 dan Patient safety dapt diberikan kepada pegawai rumah sakit sebagai alternatif untuk mencegah kejadian yang tidak diinginkan yaitu kecelakaan kerja pada pegawai rumah sakit sehingga mampu memberikan pelayanan yang optimal dan meminimalisir terjadinya kecelakaan kerja atau sesuatu yang tidak diinginkan.

\section{PENUTUP}

Kesehatan dan keselamatan merupakan hal yang sangat penting dan perlu diterapkan di semua tempat terutama di tempat yang mudah terjangkit atau tertular penyakit, contohnya rumah sakit. Rumah sakit merupakan sarana pelayanan yang bergerak di bidang jasa kesehatan, ini menyebabkan para petugas medis yang bekerja di rumah memiliki resiko 2-3 kali lebih besar mengalami kecelakaan akibat kerja. Namun pengetahuan terhadap kesehatan dan keselamatan kerja di Indonesia tergolong masih rendah seperti tidak memakai APD, tidak mengikuti prosedur kerja, tidak mengikuti peraturan keselamatan kerja dan bekerja tidak hati-hati, dimana dari setiap 300 tindakan tidak aman, akan terjadi 1 (satu) kali kecelakaan. Tujuan dari diterapkannya K3 ini pada Rumah Sakit, menurut peraturan Menkes adalah terciptanya cara kerja, lingkungan kerja yang sehat, aman, nyaman, dan dalam rangka meningkatkan derajat kesehatan karyawan RS. Untuk mengurangi atau menghilangkan bahaya yang dapat menyebabkan kecelakaan di tempat kerja maka diperlukan suatu 9 manajemen risiko kegiatannya meliputi identifikasi bahaya, analisis potensi bahaya, penilaian risiko, pengendalian risiko, serta pemantauan dan evaluasi.

\section{DAFTAR PUSTAKA}

Ardi, S. Z., \& Hariyono, W. (2018). Analisa Penerapan Budaya Perilaku Keselamatan dan Kesehatan Kerja di Rumah Sakit. Jurnal Kesmas Fakultas Kesehatan Masyarakat, 12(1), 15-20. Ernawati, N., \& Nurlelawati, E. (2017). Faktor-Faktor Yang Berhubungan Dengan Pelaksanaan Penerapan K3 Pada Tenaga Kesehatan di RSIA Permata Sarana Husada Periode 
Februari 2015. Jurnal Akademi Keperawatan Husada Karya Jaya, 3(1).

Hanafi, I. (2020). ANALISIS KECELAKAAN KERJA PADA PERAWAT DI RUMAH SAKIT UMUM PKU MUHAMMADIYAH GAMPING KABUPATEN SLEMAN (Doctoral dissertation, Universitas Ahmad Dahlan).

Istih, S. M. P., Wiyono, J., \& Candrawati, E. (2017). Hubungan Unsafe Action dengan Kecelakaan Kerja Pada Perawat di Rumah Sakit Panti Waluya Malang. Nursing News: Jurnal Ilmiah Keperawatan, 2(2).

Nazirah, R., \& Yuswardi, Y. (2017).

PERILAKU PERAWAT DALAM PENERAPAN MANAJEMEN KESEHATAN DAN KESELAMATAN KERJA (K3) DI ACEH. Idea nursing journal, 8(3).

Purba, H. I. D., Girsang, V. I., \& Malay, U. S. (2018). STUDI KEBIJAKAN, PERENCANAAN DAN PELAKSANAAN KESELAMATAN DAN KESEHATAN KERJA RUMAH SAKIT (K3RS) DI RUMAH SAKIT UMUM (RSU) MITRA SEJATI MEDAN TAHUN 2018. Jurnal Mutiara Kesehatan Masyarakat, 3(2), 113-124.

Ramdan, I. M., \& Rahman, A. (2018). Analisis Risiko Kesehatan dan
Keselamatan Kerja (K3) pada Perawat. Jurnal Keperawatan Padjadjaran, 5(3)

Salawati, L., Taufik, N. H., \& Putra, A. (2014). Analisis Tindakan Keselamatan dan Kesehatan Kerja Perawat dalam Pengendalian Infeksi Nosokomial di Ruang ICU RSUD dr. Zainoel Abidin Banda Aceh. Jurnal Kedokteran Syiah Kuala, 14(3), 128-134.

Salikunna, N. A., \& Towidjojo, V. D. (2011). Penerapan Sistem Manajemen Kesehatan dan Keselamatan Kerja di Rumah Sakit Bersalin Pertiwi Makassar. Biocelebes, 5(1).

Sandewa, S., \& Adhiwijaya, A. (2014). Hubungan Perilaku dengan Resiko Kecelakaan Kerja pada Perawat di Ruang Rawat Inap RSUD Labuang Baji Makassar. STIKES Nani Hasanuddin Makassar.

Simamora, R. H. (2018). Buku ajar keselamatan pasien melalui timbang terima pasien berbasis komunikasi efektif: SBAR. Medan: USUpress.

Simamora, R. H. (2019). Buku ajar pelaksanaan identifikasi pasien. Uwais Inspirasi Indonesia.

Tamboto, C. D., Kandou, G. D., \& Kawatu, P. A. (2017). Analisis Penerapan Standar Pelayanan Kesehatan Kerja Di Rumah Sakit 
Gmim Kalooran Amurang Kabupaten

Minahasa Selatan. KESMAS, 6(4). 